\title{
Evaluation of body representation in children with hemiplegic cerebral palsy: toward the development of a neuropsychological test battery
}

\author{
Patrícia L. B. Fontes ${ }^{1,2}$, Ricardo Moura ${ }^{1}$, and Vitor Geraldi Haase ${ }^{1}$ \\ 1. Universidade Federal de Minas Gerais, Belo Horizonte, MG, Brazil \\ 2. Pontifícia Universidade Católica de Minas Gerais, Belo Horizonte, MG, Brazil
}

\begin{abstract}
Clinical observations indicate that many children with hemiplegic cerebral palsy (HCP) exhibit a lack of use or disregard of the affected upper limb. The aim of the present study was to develop, adapt, and verify the psychometric properties of a neuropsychological battery to assess body perception and representation disturbances in children with HCP. Three groups of children participated in this study, who took part in different phases of the validation process: one group of typically developing children (TD; $n=30$; aged 4-6 years) and two groups of HCP children (HCP1: $n=12$, aged 5-10 years; HCP2: $n=49$, aged 5-13 years). Because no cognitive-neuropsychological model of body representation has been specifically developed for children, the tasks were designed based on a cognitive-neuropsychological model developed for adults. The chosen model comprises three levels of body representation: body schema, body structural description, and body image. The following steps were adopted in developing the instrument: development and choice of the tasks, selection and preparation of stimuli, adequacy and improvement of the instrument, semantic analysis of items, internal consistency, and feasibility and acceptability of application for TD and HCP children. The final set of tasks and items was chosen to balance the levels of difficulty and internal consistency. We concluded that the final battery was adequate and can be used to assess body representation disturbances in children with HCP. Keywords: hemiplegic cerebral palsy, developmental disregard, body perception, body representation.
\end{abstract}

Received 18 November 2013; received in revised form 12 May 2014; accepted 14 May 2014. Available online 27 June 2014.

\section{Introduction}

Cerebral palsy (CP) is a term used to define a group of primarily motor symptoms secondary to a non-progressive lesion of the immature brain (Watkins \& Rosenberg, 2002; Morris, 2007). Hemiplegic cerebral palsy (HCP) has as one of its characteristics unilateral spastic paresis or plegia attributable to a contralateral lesion. Children with HCP show a delay in the acquisition of motor milestones and a deficit in the organization of body movements of both the upper and lower limbs (Mewasingh, Sékhara, Pelc, Missa, Cheron,

Patrícia L. B. Fontes, Ricardo Moura, and Vitor Geraldi Haase, Graduate Program in Neurosciences, Federal University of Minas Gerais. Patrícia L. B. Fontes, Pontifical Catholic University of Minas Gerais. Vitor Geraldi Haase, Department of Psychology, Federal University of Minas Gerais. Correspondence regarding this article should be directed to: Patrícia L. B. Fontes, Developmental Neuropsychology Laboratory, Department of Psychology, Universidade Federal de Minas Gerais, Avenida Antônio Carlos, 6627, Belo Horizonte, Minas Gerais, 31270-901, Brazil. E-Mail: patricia.lemos.b.fontes@gmail.com
\& Dan, 2004; Bax et al., 2005). However, the modern definition of CP goes beyond motor deficits. Sensory and perceptual impairments, cognitive deficits, and learning or behavioral disorders frequently accompany the motor deficits (Bax et al., 2005; Morris, 2007; Rethlefsen, Ryan, \& Kay, 2010).

Clinical observations indicate that many children with HCP exhibit functional alterations in the hemiparetic upper limb that resemble somatoagnosic or motor neglect disorders encountered in adults with acquired hemiplegia. The term "developmental disregard" has been proposed to characterize a "failure to use the potential motor functions and capacities of the affected arm and hand for spontaneous use in daily life" (Houwink, Aarts, Geurts, \& Steenbergen, 2011, p. 2158). In bimanual tasks, these children frequently fail to engage the hemiparetic limb as support for the healthy limb, a behavior that is similar to motor neglect (Punt \& Riddoch, 2006). While tying shoelaces, they fail to use the paretic hand as an assistive device. In other circumstances, the children ignore the affected superior limb, which lays passive, sometimes in awkward, dysfunctional positions. Some children may even stay seated for minutes over the paretic limb. In 
other cases, children develop negative attitudes in relation to the affected limb (i.e., anosodiaphoria and misoplegia; Loetscher, Regard, \& Brugger, 2006), complaining about the inert limb or referring to it as a "thing." Occasionally, the children may refuse to use the paretic upper limb and, although less frequently, they may even remove the corresponding limbs from toys.

Nevertheless, research in this field is still scarce, and a search of the PubMed database as of February 2014 indicated that the neuropsychological literature on body representation and body perception in HCP is relatively scarce (Houwink et al., 2011; Frassinetti et al., 2012). Houwink et al. (2011) suggested that attentional deficits and a lack of automatization may be related to limb disuse and disregard, but these observations also suggest that body representation may be impaired in children with HCP. If present, impairments in body representation could hinder physical therapy and other rehabilitative efforts in these individuals. We investigated body representation in children with HCP.

References to disorders of body representation were also found in older literature (Ajuriaguerra \& Stucki, 1969). According to these authors, children with HCP appear to ignore the affected limb or have no awareness of it and are not able to look at the paralyzed limb or even use it. Ajuriaguerra and Stucki (1969) asserted that the functional deficits of the affected limb presented by children with HCP may not be thoroughly explained by motor difficulties. The authors also raised the hypothesis that perceptual-visual disorders may aggravate motor disorders. According to Katz, Cermak, and Shamir (1998), unilateral neglect may affect the ability to assimilate visual information of the environment, one of the main cognitive mechanisms by which the child acquires representations of the world. They also showed evidence that deficits in the visuospatial allocation of attention may have direct implications in the education and rehabilitation of the child.

In contrast to the relative scarcity of neuropsychological studies on body representation in hemiplegic children, advances have been made in the characterization of body representation both in functional neuroimaging studies (Downing, Jiang, Shuman, \& Kanwisher, 2001; Peelen \& Downing, 2005, 2007; Schwarzlose, Baker, \& Kanwisher, 2005; Morris, Pelphrey, \& McCarthy, 2006; Peelen, Wiggett, \& Downing, 2006; Peelen, Atkinson, Andersson, \& Vuilleumier, 2007; Taylor, Wiggett, \& Downing, 2007) and studies of impairments in adults with acquired hemiplegia (Sirigu, Grafman, Bressler, \& Sunderland, 1991; Sirigu, Duhamel, Cohen, Pillon, Dubois, \& Agid, 1996; Coslett, 1998; Buxbaum \& Coslett, 2001; Schwoebel, Buxbaum, \& Coslett, 2004; Gialanella, Monguzzi, Santoro, \& Rocchi, 2005; Schwoebel \& Coslett, 2005; Punt \& Riddoch, 2006).

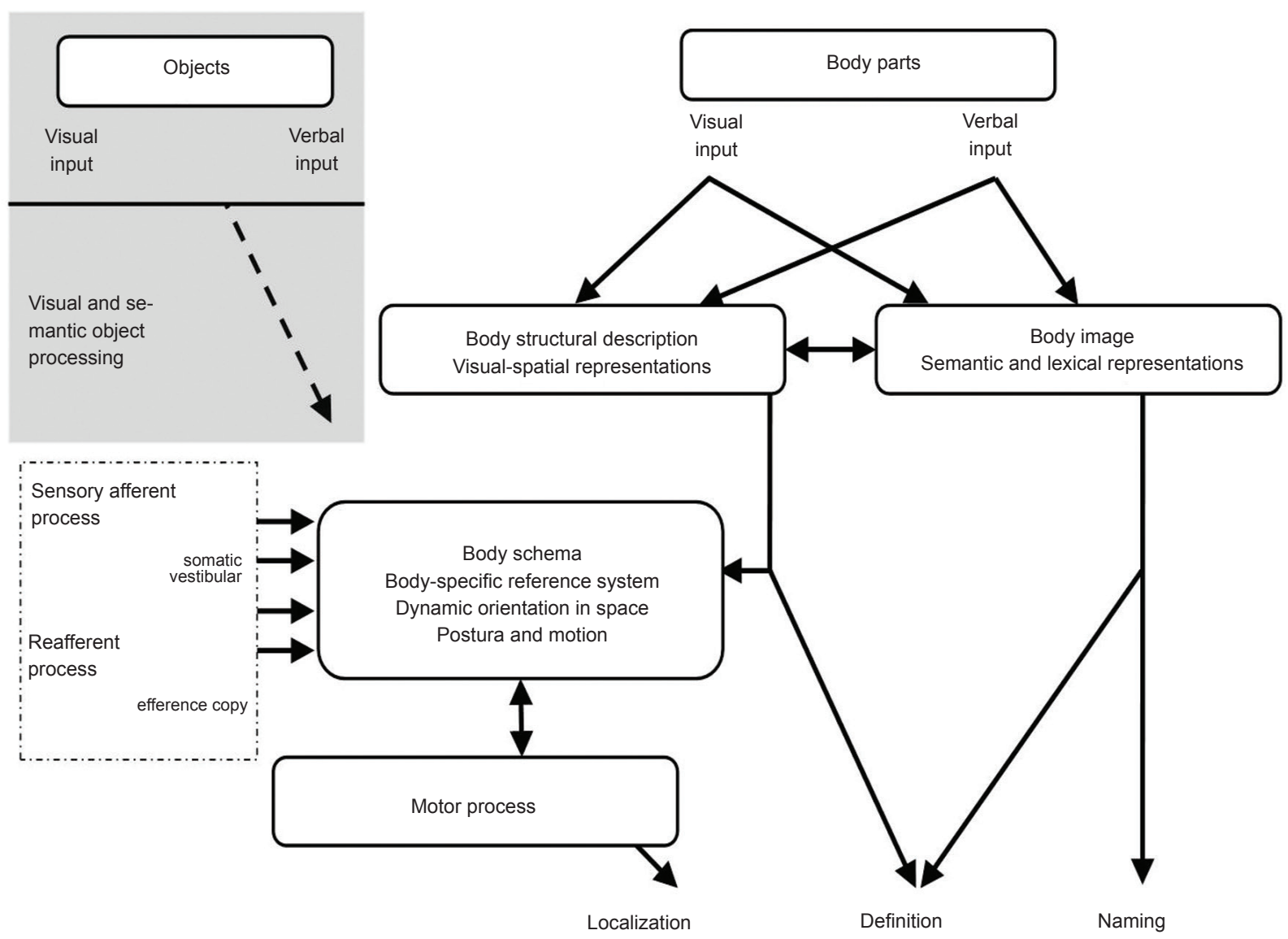

Figure 1. Cognitive-neuropsychological model comprising three levels of body representations (modified from Sirigu et al., 1991). 


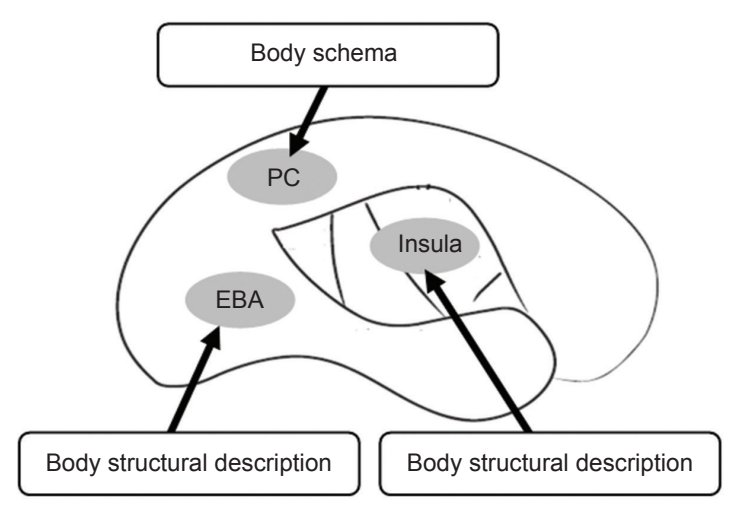

Figure 2. Cortical localization of main body representation domains (modified from Berlucchi \& Agliotti, 2009). PC, posterior parietal cortex; EBA, extrastriate body area.

Body awareness or the perception of one's own body constitutes a fundamental process to control action (Murata \& Ishida, 2007). Information on the configuration or perception of one's own body is provided by visual and somatosensory afferents and by the monitoring of motor commands by means of proprioceptive feedback of the motor execution (Goldenberg, 2002; Murata \& Ishida, 2007). The mental representation of the body is progressively elaborated thanks to sensory afferents that, from the beginning of life, maintain a link with motricity (Case-Smith, Allen, \& Pratt, 2001). Based on the model of multiple sensory afferents, Sirigu et al. (1991) proposed the first systematic cognitiveneuropsychological description of body representations (Figure 1). This cognitive-neuropsychological model suggests that the processing of body-related knowledge comprises several representations, with at least three distinct types of representations that contribute to body knowledge. (1) Body schema (BS) is the emergent body-reference system that supplies information about the online representations of the body parts. These representations are dynamic and proprioceptive in nature, providing information about the position and changes in positions of body parts. It is a polymorphous system that emerges from various sources of sensory information, including somatosensory homunculi and somatic and vestibular afferences. (2) Body structural description (BSD) is visual in nature, and it allows the individual to specify the position and limits of each part of the body. These representations contain the categoryspecific visuospatial representations of an individual's own body and also bodies in general. (3) Body image (BI) contains semantic and lexical information about body parts, such as naming, defining functional relations that exist between parts of the body, and associating them with emotions or artifacts. These representations are likely to be more strongly linked to the verbal systems.

Growing knowledge derived from both functional neuroimaging and patient studies indicates that, among others, distinct cortical areas contribute to the implementation of these three types of body representation (Berlucchi \& Agliotti, 2009). Body schema has been linked to the posterior parietal cortex, and BSD and BI are associated with the ventral lateral occipito-temporal transition (extrastriate body area) and insula, respectively (Figure 2). The functional role of these areas should be interpreted as "hubs" or "portals" that link a complex network of associated cortical and subcortical structures (Mesulam, 1998). Their critical role in implementing the associated forms of body representations should be established by studies that investigate specific forms of body knowledge impairment after the corresponding lesions.

We sought to develop a battery of neuropsychological tasks that assess in children the most frequent dimensions of body representation that are impaired in adults with acquired hemiplegia. As a first approximation, the cognitive-neuropsychological model of body representation derived from adults was chosen as a framework (Sirigu et al., 1991). In this paper we describe the development of the tasks by considering their selection and adaptation for use with children, the construction and selection of stimuli, and the feasibility and acceptability of application in typically developing children and children with HCP.

\section{Methods}

\section{Participants}

Three groups of children participated at different stages in the development of the task battery. In the first stage, one group that was composed of typically developing children (TD; $n=30$, mean age $=5$ years 2 months, $\mathrm{SD}=9.82$ months) was assessed to evaluate the intelligibility of stimuli and acceptance of instructions. All of the TD children were recruited at a private school in a major urban center in southeast Brazil (Belo Horizonte, Minas Gerais). We chose to test younger children in this phase to ensure the adequacy of stimuli and instructions for HCP children, who usually exhibit normal but lower general cognitive abilities. Next, one group that was composed of children with HCP (HCP1; $n=12$, mean age $=8$ years 4 months, $\mathrm{SD}=$ 18.60 months) participated in the semantic analysis of the items. An additional group of children with HCP $(\mathrm{HCP} 2 ; n=49$, mean age $=8$ years 5 months, $\mathrm{SD}=19.78$ months) participated in the psychometric investigation of the battery for clinical populations. Children from both HCP groups were recruited at a physical therapy outpatient facility at a large private university in the same region. To participate in the study, all of the children were required to have normal or corrected-to-normal vision. Exclusion according to visual field defects was clinically performed using confrontation perimetry. The presence of unilateral visual neglect was also clinically determined using double simultaneous stimulation. Participation in the study required written informed consent by the parents and oral consent by the children. 
Table 1. Task summary according to body representation level.

\begin{tabular}{|c|c|c|}
\hline $\begin{array}{l}\text { Level of body } \\
\text { representation }\end{array}$ & Tasks & References \\
\hline \multirow[t]{4}{*}{ Body Schema } & $\begin{array}{l}\text { Hand Matching } \\
\text { (Viewing Angle } \\
\text { Effect) }\end{array}$ & $\begin{array}{l}\text { Marmor (1977), Buxbaum et } \\
\text { al. (2000) }\end{array}$ \\
\hline & Hand Laterality & $\begin{array}{l}\text { Parsons (1987), Parsons et al. } \\
\text { (1995), Coslett (1998), Bux- } \\
\text { baum et al. (2000), Coslett et al. } \\
\text { (2002), Schwoebel et al. (2004), } \\
\text { Schwoebel \& Coslett (2005) }\end{array}$ \\
\hline & $\begin{array}{l}\text { Imitation of } \\
\text { Meaningful } \\
\text { Gestures }\end{array}$ & $\begin{array}{l}\text { Buxbaum et al. (2000), Schwoe- } \\
\text { bel et al. (2004) }\end{array}$ \\
\hline & $\begin{array}{l}\text { Imitation of } \\
\text { Meaningless } \\
\text { Gestures }\end{array}$ & $\begin{array}{l}\text { Goldenberg (1995), Sirigu et al. } \\
\text { (1996), Buxbaum et al. (2000), } \\
\text { Schwoebel et al. (2004) }\end{array}$ \\
\hline \multirow[t]{3}{*}{$\begin{array}{l}\text { Body } \\
\text { Structural } \\
\text { Description }\end{array}$} & $\begin{array}{l}\text { Visual Body Part } \\
\text { Localization }\end{array}$ & $\begin{array}{l}\text { Sirigu et al. (1991), Buxbaum } \\
\text { \& Coslett (2001); Coslett et al. } \\
\text { (2002), Schwoebel et al. (2004), } \\
\text { Schwoebel \& Coslett (2005) }\end{array}$ \\
\hline & $\begin{array}{l}\text { Verbal Body Part } \\
\text { Localization }\end{array}$ & $\begin{array}{l}\text { Sirigu et al. (1991), Buxbaum } \\
\text { \& Coslett (2001), Coslett et al. } \\
(2002)\end{array}$ \\
\hline & $\begin{array}{l}\text { Matching Body } \\
\text { Parts by Loca- } \\
\text { tion }\end{array}$ & $\begin{array}{l}\text { Coslett et al. (2002), Schwoebel } \\
\text { \& Coslett (2005) }\end{array}$ \\
\hline \multirow[t]{3}{*}{ Body Image } & $\begin{array}{l}\text { Matching Body } \\
\text { Parts by Func- } \\
\text { tion }\end{array}$ & $\begin{array}{l}\text { Sirigu et al. (1991), Coslett et al. } \\
\text { (2002), Schwoebel et al. (2004), } \\
\text { Schwoebel \& Coslett (2005) }\end{array}$ \\
\hline & $\begin{array}{l}\text { Body Parts and } \\
\text { Object Associ- } \\
\text { ation }\end{array}$ & $\begin{array}{l}\text { Buxbaum \& Coslett (2001), } \\
\text { Coslett et al. (2002) Schwoebel } \\
\text { \& Coslett (2005) }\end{array}$ \\
\hline & $\begin{array}{l}\text { Naming Body } \\
\text { Parts }\end{array}$ & $\begin{array}{l}\text { Sirigu et al. (1991), Coslett et } \\
\text { al. (2002) }\end{array}$ \\
\hline
\end{tabular}

The research procedures were previously approved by the local advisory board (ETIC 250/09, COEP-UFMG). All of the children were individually assessed in silent rooms at the school or outpatient clinic.

\section{General cognitive ability}

Intelligence was assessed using Raven's Coloured Progressive Matrices (Angelini, Alves, Custódio, Duarte, \& Duarte, 1999).

\section{Choice of tasks}

Ten tasks that were derived from adult neuropsychological studies were chosen to compose the set of instruments. Categorization was based on a current cognitive-neuropsychological model (Sirigu et al., 1991) that identified three different domains of body representation (Sirigu et al., 1991; Coslett, 1998; Buxbaum \& Coslett, 2001; Coslett, Saffran, \& Schwoebel, 2002; Schwoebel et al., 2004; Schwoebel \& Coslett, 2005). The tasks are summarized in Table 1 and are described in more detail below.

\section{Tasks that assess body schema}

Hand Matching Task. According to Parsons et al. (1995), decisions about hand laterality are made by mentally rotating one's own motor hand image. Because it demands internal movements of body parts, to match the position of presented pictures, the Hand Matching Task relies on internal and dynamic representations of the hands (i.e., on BS). To assess the viewing angle effect, pictures of two hands were simultaneously presented on the computer screen at two different viewing angles according to modified procedures that were previously adopted by Marmor (1977) and Buxbaum, Giovannetti, and Libon (2000). The children were asked to decide whether the hands had the same laterality or not. The child was verbally instructed in the following way: "You must say equal if both hands are from the same side, and different if they are from opposite sides." The stimuli consisted of pictures of the hand's dorsum in different positions. In four pictures, the dorsum of the hand was frontally presented with the fingers pointing medially or down. In another set of four pictures, the dorsum of the hand was presented at a $45^{\circ}$ rotated angle with the fingers pointing medially or down. The eight stimuli were used in 16 equally distributed trials.

Hand Laterality Task. For decisions on hand laterality, one must imagine the hand moving from its current position to the one presented in the picture (Parsons, 1987; Parsons et al., 1995; Coslett et al., 2002). According to these authors, this decision is highly related to the hand's current position. Therefore, the Hand Laterality Task relies on the hand's internal proprioceptive representations. Pictures of single hands were presented on the computer screen, and the child was asked to emit a verbal response (i.e., say whether it was the right or left hand; Parsons, 1987; Parsons et al., 1995; Coslett, 1998; Buxbaum et al., 2000; Coslett et al., 2002; Schwoebel et al., 2004; Schwoebel \& Coslett, 2005). The child was given the following verbal instructions: "Say right if the right hand is presented and left if the left one is presented." Twelve photographs of hands were presented on the computer screen. The stimuli were six photographs of human hands in different positions (i.e., dorsal, palmar, and lateral rotated views of the hands with fingers pointing medially or down). The proportion of right- to left-hand trials was $6: 6$.

Imitation of Meaningful Gestures Task. According to Goldenberg (2002), because an external reference is not provided, gesture imitation can be defined as requiring a particular body configuration. Therefore, tasks that tap into the imitation of meaningful gestures assess BS because they demand proper body representation. The stimuli for meaningful gesture imitation were presented on the computer screen, and the child was instructed to correctly imitate the gesture, regardless of laterality (Buxbaum et al., 2000; Schwoebel et al., 2004). The child was given the following verbal 
instructions: "Imitate correctly the presented gesture." The meaningful gestures were 10 animations of waving goodbye, asking for silence, military salute, pointing straight ahead, "OK" sign, "no" sign, sending a kiss, "stop" sign, clapping hands, and pointing to one side. The representations in all of the trials were of the right upper limb/hand.

Imitation of Meaningless Gestures Task. Similar to meaningful gesture imitation, tasks that assess the production of meaningless gestures also assess BS because they also demand a proper mental representation of the body. The stimuli for meaningless gesture imitation were 10 pictures, five that depicted the fingers in specific positions and five that displayed arbitrary positioning of the upper limb in relation to the trunk and head. As in the preceding task, the items were presented on the computer screen, and the child was instructed to correctly imitate the gesture, regardless of laterality (Goldenberg, 1995; Sirigu et al., 1996; Buxbaum et al., 2000; Schwoebel et al., 2004). The child was given the following verbal instructions: "Correctly imitate the presented gesture."

\section{Tasks that assess body structural description}

Visual Body Part Localization Task. Evidence shows that BSD integrity is needed to perform any task that requires visual recognition of the body (Sirigu et al., 1991; Buxbaum \& Coslett, 2001; Coslett et al., 2002; Schwoebel et al., 2004; Schwoebel \& Coslett, 2005). The child was instructed to point to his/her own body part that was shown on the screen (visual stimuli, $\mathrm{k}=20$; Sirigu et al., 1991; Buxbaum \& Coslett, 2001; Coslett et al., 2002; Schwoebel et al., 2004; Schwoebel $\&$ Coslett, 2005). The child was verbally instructed to "Point on your body to the same body part presented." The visual stimuli were composed of pictures of 20 pseudorandomized isolated body parts (hair, belly, foot, mouth, ankle, arm, leg, knee, neck, shoulder, face, nose, head, elbow, ear, chest, eye, hand, back, and wrist). The responses were coded as correct if the child identified (pointed to) the correct body part, regardless of laterality.

Verbal Body Part Localization Task. Evidence shows that BSD integrity is also necessary in tasks that require the ability to point to body parts that are named by the examiner (Sirigu et al., 1991; Buxbaum \& Coslett, 2001; Coslett et al., 2002). The child was asked to point to a body part named by the examiner (verbal stimuli, $\mathrm{k}=20$; Sirigu et al., 1991; Buxbaum \& Coslett, 2001; Coslett et al., 2002). The child was verbally instructed to "Point on your body to the named body part." The verbal stimuli consisted of the name of the 20 body parts used in the visual stimulation, which were clearly said by the examiner. The responses were coded as correct if the child identified (pointed to) the correct body part, regardless of laterality.
Matching Body Parts by Location Task. As defined by Sirigu et al. (1991), tasks that require the recognition of the position and limits of body parts are preferentially associated with the BSD system. The stimuli consisted of four body part pictures that were simultaneously presented on the computer screen. One sample picture was presented above, and the three test pictures were arranged in a row below. The child was asked to point among the three pictures in the lower row to the one that was the physical continuation of the single picture depicted above (Coslett et al., 2002; Schwoebel \& Coslett, 2005). The child was verbally instructed to "Point to the figure of the body part that is nearer or continues the figure of XXX." For example, in one trial with a sample figure that represented a leg, the child should point to the foot picture (among the foils were ear and hand). The position of the correct choice in the lower row was pseudorandomized. Eleven trials were conducted.

\section{Tasks that assess body image}

Matching Body Parts by Function Task. According to Sirigu et al. (1991), tasks that require bodyrelated semantic and lexical representations, such as recognizing the functionality of body parts, are related to BI integrity. In this task, the child was instructed to match body parts according to their function (Sirigu et al., 1991; Coslett et al., 2002; Schwoebel et al., 2004; Schwoebel \& Coslett, 2005). The stimuli were four body part pictures displayed on the computer screen. The sample figure was located above, with the target and two foils displayed in a lower row. The task was to choose which of the body parts depicted in the lower row had a similar function as the sample picture or was "doing similar things." The child was asked to choose (point to or say the name of) the body part picture that most closely matched the reference picture. The child was verbally instructed to "Point to or say the name of the figure that is doing similar things as the figure of XXX."For example, in one trial, the sample figure was a leg. The correct response was the arm, and the foils were the shoulder and ear. The sample body parts were nine pictures of isolated body parts displayed in a pseudorandom order.

Body Parts and Object Association Task. The association of body parts with objects also taps into BI because they are related to the lexical and semantic knowledge of body parts (Sirigu et al., 1991). The stimuli were displayed on the computer screen. The sample picture that depicted a grooming tool or clothing/adornment item was located above, and the child was asked to choose (point to or say the name of) the item that represented a matching body part from the three pictures in the lower row (Buxbaum \& Coslett, 2001; Coslett et al., 2002; Schwoebel \& Coslett, 2005). The child was verbally instructed to "Point to or say the name of the item that is related to the figure of XXX." For example, in one trial, the sample was a watch, and 
the correct response was the wrist. The foils were the ankle and elbow. Eleven trials were conducted.

Naming Body Parts Task. Like the previously described tasks that assess BI, the capacity of naming body parts involves lexical and semantic information (Sirigu et al., 1991). The child was asked to name 20 isolated body parts that were presented one at a time on the screen (Sirigu et al., 1991; Coslett et al., 2002). The child was verbally instructed to "Say the name of the presented picture." The same stimuli were used as in the Visual and Verbal Body Part Localization Tasks. In all of the tasks, no time limit was imposed, but the child was solicited to respond immediately after presentation.

\section{Preparation of photographic and video stimuli}

According to the items listed in the task descriptions, 189 stimuli were constructed. Twenty-four were rightand left-hand photos in various positions. Twenty-five pictures depicted meaningless gestures. Twenty videos displayed meaningful gestures. Seventy-six were photos of isolated body parts. Forty-four showed body-related objects. The parts of the body were photographically recorded, and the execution of gestures with and without meaning was recorded by video using a Sony VX DCS-H9 digital video camera. The body parts and gestures were depicted by a young female model who wore a tight-fitting black costume that consisted of a blouse and leggings. The hair was arranged in a bun, and the model wore no accessories or make-up. The model was instructed to adopt a neutral emotional posture and facial expression. A series of common gender-neutral objects and clothes was also selected and photographically depicted. The images were recorded under sunlight without a flash, with distances between the camera and model or object varying from 30 to 80 $\mathrm{cm}$. Every stimulus was depicted in four photographs from different angles (front, side, and top) and over different neutral backgrounds (white and black). Six photographs of body parts and one video with the human model were selected for graphical digital design. The drawings were first elaborated on paper and later animated using FLASH software.

\section{Choice of stimuli}

Three judges with a graduate background in neuropsychological research and assessment helped with stimulus selection. The judges worked collectively in two different sessions 1 week apart, lasting approximately $2 \mathrm{~h}$ each. In the first meeting, the judges were briefed on the study goals, and the rationale for each task was discussed in detail. In the second meeting, the stimuli were presented individually by means of a PowerPoint presentation with DataShow. The presentation time varied according to the judges' requests. Four depictions of each stimulus were presented, and the judges were instructed to choose the clearest and most easily identifiable one. Only one depiction could be chosen for each stimulus. The judges were allowed to suggest possible different compositions of angle and background. Each judge received a response booklet. The judges marked the preferred stimulus with an $\mathrm{X}$. The choice remained blank if no stimulus was considered suitable. The choices were individual and anonymous. No discussion was allowed among the judges. Finally, the judges were asked to choose between model photographs/videos and digital graphic modalities.

\section{Graphic design}

A graphic designer reproduced as exactly as possible the selected pictures, preserving angle of vision, using a white background, and avoiding color and brightness variations. The digital videos were of the same duration as the ones with the female model, and the gestures were executed at a slow speed.

\section{First version of the instrument}

Each stimulus received a number label, and a sequence of stimuli was established in pseudorandom order to compose each task. The sequence of tasks was also pseudorandomly established.

\section{Adequacy and improvement of the instrument}

To assess the comprehension of stimuli and comprehension and acceptance of instructions given to the children, the first version of the tasks was applied to the TD group. The children's comments and responses were recorded in written form. Written notes were then analyzed, thus guiding the final formulation of instructions. In this phase, item and task difficulty were assessed to improve the instrument through the exclusion of items and tasks with accuracy lower than $20 \%$. Higher difficulty indices were indicated by lower hit rates. Task difficulty was estimated by percent accuracy (i.e., the total score for each participant divided by the total number of items). We also assessed the sequence of test presentation and the time required for application.

\section{Semantic analysis of items}

To verify whether the tasks were understandable to the target population, the second improved version of the tasks, developed after initial assessments of their adequacy for typical preschoolers, was applied to a sample of 12 children with hemiplegia (HCP1). The acceptance and duration of application in the target population were assessed at this moment. The examiners paid attention to eventual difficulties encountered by HCP children.

\section{Internal consistency}

To assess the internal consistency of the items and tasks, the second version of the instrument was applied in an additional group of 49 children with hemiplegia (HCP2). The internal consistency of the items was assessed using the Kuder-Richardson (K-R20) formula. For the final 
selection of the items, we used two criteria: item difficulty and K-R20 value (reliability). All of the items with a hit rate of $100 \%$ and K-R20 lower than .60 were eliminated.

\section{Results}

\section{Participants}

All of the TD participants had normal intelligence as assessed by Raven's Coloured Progressive Matrices (mean $\mathrm{z}=.79, \mathrm{SD}=.78$ ) and had no major sensory, motor, or other neurological impairments. All of the HCP children had a diagnosis of hemiplegic cerebral palsy, normal intelligence as assessed by the Raven test (HCP1: mean $\mathrm{z}=-.46, \mathrm{SD}=.67$; HCP2: mean $\mathrm{z}=-.52$, $\mathrm{SD}=.75$ ), and no major auditory or visual deficits or uncontrolled seizure disorders.

\section{Choice of stimuli}

From the 189 initial stimuli, 58 photos and 10 videos were chosen, for a total of 68 stimuli (Table 2). The following stimuli did not receive votes and were consequently considered inadequate: forearm, hip, thigh, and calf. The three judges voted for the digital version with the white background. Two of the three judges suggested using a red circle to emphasize some body parts: neck, shoulder, forearm, and knee.

Table 2. Final set of pictures by category.

\begin{tabular}{lc}
\hline Stimuli & Number of pictures \\
\hline Right hand & 06 \\
Left hand & 06 \\
Meaningless hand gestures & 05 \\
Meaningless hand-head gestures & 05 \\
Meaningful gestures (video) & 10 \\
Single body parts & 25 \\
Objects and clothing & 11 \\
\hline Total & 68 \\
\hline
\end{tabular}

\section{Graphic design}

According to the judges' decisions, all of the stimuli were digitally redrawn over a white background. Figure 3 presents three examples of this digitalization.

\section{First version of the instrument}

Two preliminary sequences of application were pseudorandomly established in the first version of the instrument, which are shown in Table 3. The sequences were sequentially applied so that half of the children solved one sequence and the other half solved the other.

\section{Adequacy and improvement of the instrument}

Observations during testing with the TD group indicated that the stimuli were well accepted by these children, who became interested in them. None of

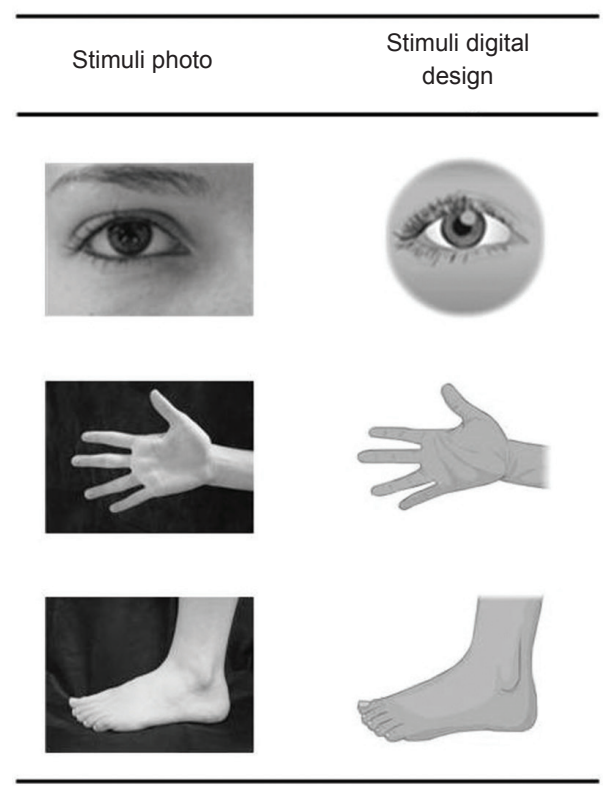

Figure 3. Digitalization of three stimuli.

the children asked to interrupt testing or experienced difficulties understanding the instructions. Inadequacies were identified for some of the stimuli. The children experienced difficulties recognizing two verbal stimuli (wrist and ankle) used in the Verbal Body Part Localization Task. Ninety percent of the children were unable to point to the wrist, and $87 \%$ of the children were

Table 3. First version of the instrument: Description of the order of tasks in sequences 1 and 2 .

\begin{tabular}{ll}
\hline Sequence 1 & Sequence 2 \\
\hline Naming Body Parts (BI) & $\begin{array}{l}\text { Imitation of Meaningful } \\
\text { Gestures (BS) }\end{array}$ \\
$\begin{array}{l}\text { Imitation of Meaningful } \\
\text { Gestures (BS) }\end{array}$ & $\begin{array}{l}\text { Imitation of Meaningless } \\
\text { Gestures (BS) }\end{array}$ \\
Imitation of Meaningless & Naming Body Parts (BI) \\
Gestures (BS) & \\
Visual Body Part Localization & Hand Matching - Effect of \\
(BSD) & Viewing Angle (BS) \\
Verbal Body Part Localization & $\begin{array}{l}\text { Raven's Coloured Progressive } \\
\text { (BSD) }\end{array}$ \\
Matrices \\
Viewd Matching - Effect of & Matching Body Parts by \\
Matching Body Parts by & Location (BSD) \\
Function (BI) & Hand Laterality (BS) \\
Matching Body Parts by & Visual Body Part Localization \\
Location (BSD) & (BSD) \\
Hand Laterality (BS) & Verbal Body Part Localization \\
Body Parts and Object & (BSD) \\
Association (BI) & Matching Body Parts by \\
Raven's Coloured Progressive & Function (BI) \\
Matrices & Body Parts and Object \\
\hline BI, bociation (BI)
\end{tabular}

BI, body image; BS, body schema; BSD, body structural description. 
unable to point to the ankle in this task. However, the same body parts were recognized without difficulty in the corresponding Visual Body Part Localization Task. Therefore, we eliminated the wrist and ankle from the Verbal Body Part Localization Task. Thus, the two Body Part Localization Tasks maintained a different number of stimuli: 18 stimuli for the verbal task and 20 for the visual task. Ninety percent of the children were unable to identify the wrist, and $83 \%$ were unable to identify the ankle in the Naming Body Parts Task. Thus, these stimuli were also eliminated, and 18 stimuli remained.

A generally low accuracy rate $(28.33 \%)$ was observed in the Hand Matching (Viewing Angle Effect) Task. Because of this, this task was eliminated. Fourand five-year-old children were unable to understand this task. They said that the hands belonged to the same person or responded randomly. Six-year-olds exhibited a somewhat higher level of comprehension of the Hand Matching (Viewing Angle Effect) Task, but the accuracy was also low $(42.59 \%)$.

In the Hand Laterality Task, besides giving an oral response, the children tended to raise their own corresponding hand. Based on this behavior, we opted to divide this task into two tasks: oral response and motor response (Oral Hand Laterality and Motor Hand Laterality Tasks). The same sequence of 12 figures of hands, previously defined by drawings, were presented twice from then on. In the first presentation, the child was asked to present a verbal response (i.e., say whether the hand shown on the monitor was the left or right one). In the second task, the child had to give a motor response (i.e., show [or raise] the same hand shown in the picture).

Regarding the sequence of application, the Matching Body Parts by Location Task should not precede the Matching Body Parts by Function Task. This occurred in sequence 2 (see Table 3), and the resulting accuracy of the Matching Body Parts by Function Task was lower (59.26\% vs. $77.03 \%$ in sequence 1$)$. Thus, we decided to invert the position of these two tasks in sequence 2 to position the Matching Body Parts by Function Task before the Matching Body Parts by Location Task.

Because of the influence of the Matching Body Parts by Location Task on the Matching Body Parts by Function Task and because they are tasks with similar layouts, in which the child should point to one among three figures of body parts, we decided to adapt the set of responses of the Matching Body Parts by Function Task. Thus, for the Matching Body Parts by Function Task, no figure remained among the three distracting figures that were related in terms of continuity to the reference picture. A new sequence was pseudorandomly established, and we substituted only the confusing items. The first, second, and fifth sets were altered. The lower part of the trunk was replaced by the shoulder, the arm was replaced by the eye, and the leg without a foot was replaced by the upper trunk.

The minimum and maximum times of application were 52 and $70 \mathrm{~min}($ mean $=63.97 \mathrm{~min}, \mathrm{SD}=3.76$
Table 4. Second version of the instrument: Description of the order of tasks in sequences 1 and 2.

\begin{tabular}{|c|c|}
\hline Sequence 1 & Sequence 2 \\
\hline Naming Body Parts (BI) & $\begin{array}{l}\text { Imitation of Meaningful } \\
\text { Gestures (BS) }\end{array}$ \\
\hline $\begin{array}{l}\text { Imitation of Meaningful } \\
\text { Gestures (BS) }\end{array}$ & $\begin{array}{l}\text { Imitation of Meaningless } \\
\text { Gestures (BS) }\end{array}$ \\
\hline $\begin{array}{l}\text { Imitation of Meaningless } \\
\text { Gestures (BS) }\end{array}$ & Naming Body Parts (BI) \\
\hline $\begin{array}{l}\text { Visual Body Part Localization } \\
\text { (BSD) }\end{array}$ & $\begin{array}{l}\text { Raven's Coloured Progressive } \\
\text { Matrices }\end{array}$ \\
\hline $\begin{array}{l}\text { Verbal Body Part Localization } \\
\text { (BSD) }\end{array}$ & $\begin{array}{l}\text { Matching Body Parts by } \\
\text { Function (BI) }\end{array}$ \\
\hline $\begin{array}{l}\text { Matching Body Parts by } \\
\text { Function (BI) }\end{array}$ & Oral Hand Laterality Task (BS) \\
\hline $\begin{array}{l}\text { Matching Body Parts by } \\
\text { Location (BSD) }\end{array}$ & Motor Hand Laterality Task(BS) \\
\hline Oral Hand Laterality Task (BS) & $\begin{array}{l}\text { Visual Body Part Localization } \\
\text { (BSD) }\end{array}$ \\
\hline Motor Hand Laterality Task (BS) & $\begin{array}{l}\text { Verbal Body Part Localization } \\
\text { (BSD) }\end{array}$ \\
\hline Body Parts and Object & Matching Body Parts by \\
\hline Association (BI) & Location (BSD) \\
\hline $\begin{array}{l}\text { Raven's Coloured Progressive } \\
\text { Matrices }\end{array}$ & $\begin{array}{l}\text { Body Parts and Object } \\
\text { Association (BI) }\end{array}$ \\
\hline
\end{tabular}

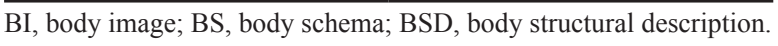

min). After the stage of adequacy and improvement, the second version of the instrument was established. The two final sequences of the second version of the instrument are shown in Table 4.

\section{Semantic analysis of items}

To assess their semantic adequacy, the tasks were applied to the HCP1 group. The children were able to complete the series of tests. It was unnecessary to make any alterations in the final version of the instrument. The HCP1 children were slower to conclude the series of tests. The minimum application time for the entire series was $75 \mathrm{~min}$.

\section{Internal consistency}

According to the item selection criteria, 56 items were eliminated. From these, 21 presented a hit rate of $100 \%$, and 35 had K-R20 coefficients lower than .60 . The final version of the instrument was established after an analysis of internal consistency. The number of items for each task at each stage of development of the instrument and the final K-R20 coefficient are shown in Table 5 .

\section{Discussion}

Clinical observations indicate that HCP patients frequently disregard the affected upper limb, ignoring 
Table 5. Number of items for tasks (in each stage) and final K-R20 coefficient.

\begin{tabular}{|c|c|c|c|c|c|}
\hline $\begin{array}{l}\text { Level of body rep- } \\
\text { resentation }\end{array}$ & Tasks & $\begin{array}{c}\text { First } \\
\text { version }\end{array}$ & $\begin{array}{l}\text { Second } \\
\text { version }\end{array}$ & $\begin{array}{c}\text { Final } \\
\text { version }\end{array}$ & $\mathrm{K}-\mathrm{R} 2 \mathrm{O}$ \\
\hline \multirow[t]{5}{*}{ Body Schema } & Hand Matching - Effect of Viewing Angle & 16 & - & - & - \\
\hline & Motor Hand Laterality & - & 12 & 8 & .70 \\
\hline & Oral Hand Laterality & 12 & 12 & 8 & .60 \\
\hline & Imitation of Meaningful Gestures & 10 & 10 & 5 & .60 \\
\hline & Imitation of Meaningless Gestures & 10 & 10 & 8 & .66 \\
\hline \multirow{3}{*}{$\begin{array}{l}\text { Body Structural } \\
\text { Description }\end{array}$} & Visual Body Part Localization & 20 & 20 & 8 & .67 \\
\hline & Verbal Body Part Localization & 20 & 18 & 5 & .65 \\
\hline & Matching Body Parts by Location & 11 & 11 & 8 & .60 \\
\hline \multirow[t]{3}{*}{ Body Image } & Matching Body Parts by Function & 09 & 9 & 5 & .60 \\
\hline & Body Parts and Object Association & 11 & 11 & 6 & .60 \\
\hline & Naming Body Parts & 20 & 18 & 14 & .63 \\
\hline
\end{tabular}

K-R20, Kuder-Richardson.

it, showing little concern for it, and failing to use it as an auxiliary device in bimanual tasks (Ajuriaguerra \& Stucki, 1969; Houwink et al., 2011). The lack of use of the affected limb may reflect disuse or disregard. Disregard implies a central deficit in body awareness. In both cases, there may be immature or disordered development of body part representations. Within this context, we sought to develop a battery of neuropsychological tasks that assess in children the most frequent dimensions of body representation impairment in adults with acquired hemiplegia. Few studies have evaluated body repersentaion in children with $\mathrm{CP}$, consequently, few instruments are available for such an assessment. The set of tasks developed herein carefully elaborated on the stimuli from previous studies (Parsons, 1987; Sirigu et al., 1991; Goldenberg, 1995; Parsons et al., 1995; Sirigu et al., 1996; Coslett, 1998; Buxbaum et al., 2000; Buxbaum \& Coslett, 2001; Coslett et al., 2002; Schwoebel et al., 2004; Schwoebel \& Coslett, 2005), proposing a final instrument for neuropsychological evaluation, with consideration of distinct levels of body representation. In the end, the instrument was carefully tested and prepared for application in children with HCP. The main classification criterion of the tasks was based on the cognitive-neuropsychological model presented by Sirigu et al. (1991). Therefore, developing specific tasks for each of the distinct types of body representation (i.e., BS, BSD, and $\mathrm{BI}$ ) was possible.

Discrimination between the left and right hands has been frequently used to assess the integrity of BS (Parsons, 1987; Parsons et al., 1995; Coslett, 1998; Buxbaum et al., 2000; Coslett et al., 2002; Schwoebel $\&$ Coslett, 2005). Tasks that involve judgments of the laterality of the hands are considered to assess BS because one of the most frequently employed strategies consists of imaging spatial coordinate transformations in one's own body. Parsons et al. (1995) demonstrated that the right/left decision about the hands is made by a mental rotation of one's hands to match the portrayed hand in a figure. According to Coslett et al. (2002), a real representation of the body in space(i.e., "online" representation) is fundamental for left/right recognition.

The Imitation of Gestures Task was also selected to evaluate $\mathrm{BS}$ because its execution also demands a correct mental representation of the body (Goldenberg, 1995; Sirigu et al., 1996). Evidence shows that BS representations are implicated in the production, recognition, and imitation of gestures (Goldenberg, 1995; Sirigu et al., 1996; Buxbaum et al., 2000; Schwoebel et al., 2004). The imitation of previously unseen or meaningless gestures assesses the integrity of BS by requiring dynamic encoding of the position of intrinsic parts of the body. Because there is no previously acquired gesture lexicon or praxicon, the imitation of meaningless gestures requires visuosomatomotor spatial coordinate transformations of one's own body. Neuropsychological studies with adults have shown that individuals with BS impairments also display deficits in imitating both meaningful and meaningless gestures (Buxbaum et al., 2000, Schwoebel et al., 2004). Goldenberg (2002) considers that the imitation of gestures, because it does not present an external reference, may only be defined as a particular configuration of the body.

Evidence shows that BSD is a level of representation that participates in all tasks that require the visual recognition of one's own body and any action on it that is guided by vision (Sirigu et al., 1991; Buxbaum \& Coslett, 2001; Coslett et al., 2002; Schwoebel et al., 2004; Schwoebel \& Coslett, 2005). The integrity of BSD is needed to perform any task that requires visual recognition of the body. Therefore, the present study presents Body Part Localization (visual and verbal stimuli) and Matching Body Parts by Location 
Tasks to assess the visually derived BSD (Sirigu et al., 1991; Buxbaum \& Coslett, 2001; Coslett et al., 2002; Schwoebel et al., 2004; Schwoebel \& Coslett, 2005). Evidence suggests that the inability to point to the parts nominated by an examiner (autotopagnosia) is preferentially associated with a deficiency in the BSD system (Sirigu et al., 1991; Buxbaum \& Coslett, 2001). Goldenberg (2002) reviewed evidence that patients with autotopagnosia make mistakes when requested to point to parts of their own body, parts of somebody else's body, or a model of the human body.

Tasks that require the retrieval of body-related semantic and lexical representations, such as naming and defining body parts or associating body parts with grooming tools or clothing/adornment items, were chosen to assess BI (Sirigu et al., 1991; Buxbaum \& Coslett, 2001; Coslett et al., 2002; Schwoebel et al., 2004; Schwoebel \& Coslett, 2005). As defined by Sirigu et al. (1991), lexical and semantic knowledge of body parts comprises one of the levels of body representation and participates in the tasks that require the individual to use the information about the functions and other properties of the parts of the human body.

Adequacy analyses indicated the need to improve the first version of the instrument. Eliminating the wrist and ankle stimuli from the Verbal Body Part Localization Task was necessary. Despite being a task that evaluates BSD, the afferent verbal stimulus demands semantic knowledge of word meaning, which justifies the difficulty presented by the children in recognizing such stimuli. This finding may be justified by the cognitive-neuropsychological model proposed by Sirigu et al. (1991), in which there is an interconnection between BSD and BI. However, the same body parts were recognized without difficulty in the corresponding Visual Body Part Localization Task. With regard to a task that presents a visual entry and motor response, without verbal involvement, children were able to see the stimulus and point to the part of the body presented, even without knowing the name of the part involved. The digital drawings that were presented were also suitable for the task. Moreover, eliminating those stimuli in the Naming Body Parts Task was necessary. Despite the visual presentation, the verbal response also requires a semantic and lexical representation. Nevertheless, after these observations, we decided that the wrist and ankle stimuli could be used in any task that did not require naming performance.

In the Hand Laterality Task, we interpreted the tendency to move the hand presented in the figure as an indicator of probable difficulty in recognizing left/ right, which involves semantic knowledge of these concepts. We considered that the movement could help the child form a representation of the presented hand. Funk, Brugger, and Wilkening (2005) used a mental rotation task, in which children aged 5 and 6 years and adults should decide about the laterality of the hands presented in the figures. Larger response times in children suggested that covert movement execution was the strategy employed to solve the task. To expand the investigation, we chose to divide the task into two: Oral Hand Laterality Task and Motor Hand Laterality Task. We considered that the motor response, in which the child was instructed to raise the same hand presented in the figure, could better evaluate BS because it demanded only a current motor-perceptual representation of the hand's position and did not involve a more elaborate right/left concept.

In sequence 2 , after matching body parts by location, the children persevered in this behavior and experienced difficulties matching body parts by function. Because both tasks had similar layouts, we inferred that this result could be related to the increased difficulty of the semantic task. The Matching Body Parts by Function Task may demand more resources in terms of semantic knowledge.

Having completed the semantic analysis, verifying that the children with HCP are able to perform the proposed task series was possible. Therefore, we concluded that the instrument was adequate for the $\mathrm{CP}$ population and that the present study represents a contribution to the developmental neuropsychology literature because it develops and adapts an evaluation instrument that considers perception and body representation disturbances in children with HCP. Additionally, the diagnosis of disturbances related to the perception and representation of the body in children with HCP could have direct implications in the elaboration of rehabilitation strategies. Therapists should not only direct the attention of the children and their families to the impaired limb and its functional possibilities but should also help build richer and more complex representations of the body and its parts at several different levels.

\section{References}

Ajuriaguerra, J., \& Stucki, J.D. (1969). Developmental disorders of the body schema. In: P.J. Vinken, \& G.W. Bruyn (Eds.), Disorders of speech, perception and symbolic behaviour (series title: Handbook of clinical neurology, vol. 4, pp. 392-407). New York: North Holland.

Angelini, A.L., Alves, I.C.B., Custódio, E.M., Duarte, W.F., \& Duarte, J.L.M. (1999). Matrizes progressivas coloridas de Raven-Escala especial. São Paulo: Centro Editor de Teses e Pesquisas em Psicologia.

Bax, M., Goldstein, M., Rosenbaum, P., Leviton, A., Paneth, N., Dan, B., ... \& Damiano, D. (2005). Proposed definition and classification of cerebral palsy. Developmental Medicine and Child Neurology, 47, 571-576.

Berlucchi, G., \& Aglioti, S.M. (2009). The body in the brain revisited. Experimental Brain Research, 200, 25-35.

Buxbaum, L.J., \& Coslett, H.B. (2001). Specialised structural descriptions for human body parts: evidence from autotopagnosia. Cognitive Neuropsychology, 18(4), 289-306.

Buxbaum, L.J., Giovannetti, T., \& Libon, D. (2000). The role of the dynamic body schema in praxis: evidence from primary progressive apraxia. Brain and Cognition, 44(2), 166-191.

Case-Smith, J., Allen, A.S., \& Pratt, P.N. (2001).Occupational therapy for children, 4th ed. St. Louis: Mosby.

Coslett, H. B. (1998). Evidence for a disturbance of the body schema in neglect. Brain and Cognition, 37, 527-544. 
Coslett, H. B., Saffran, E. M., \& Schwoebel, J. (2002). Knowledge of the human body: a distinct semantic domain. Neurology, 59(33), 357-363.

Downing, P. E., Jiang, Y., Shuman, M., \& Kanwisher, N. (2001). A cortical area selective for visual processing of the human body. Science, 293, 2470-2473.

Frassinetti, F., Fiori, S., D’Angelo, V., Magnani, B., Guzzetta, A., Brizzolara, D., \& Cioni, G. (2012). Body knowledge in braindamaged children: a double-dissociation in self and other's body processing. Neuropsychologia, 50, 181-188.

Funk, M., Brugger, P., \& Wilkening, F. (2005). Motor processes in children's imagery: the case of mental rotation of hands. Developmental Science, 8, 402-408.

Gialanella, B., Monguzzi, V., Santoro, R., \& Rocchi, S. (2005). Functional recovery after hemiplegia in patients with neglect: the rehabilitative role of anosognosia. Stroke, 36, 2687-2690.

Goldenberg, G. (1995). Imitating gestures and manipulating a manikin: the representation of the human body in ideomotor apraxia. Neuropsychologia, 33, 63-72.

Goldenberg, G. (2002). Body perception disorders. In: V.S. Ramachandran (Ed.), Encyclopedia of the human brain (vol. 1, pp. 443-458). San Diego: Academic Press.

Houwink, A., Aarts, P. B., Geurts, A. C., \& Steenbergen, B. (2011). A neurocognitive perspective on developmental disregard in children with hemiplegic cerebral palsy. Research in Developmental Disabilities, 32(6), 2157-2163.

Katz, N., Cermak, S., \& Shamir, Y. (1998). Unilateral neglect in children with hemiplegic cerebral palsy. Perceptual and Motor Skills, 86, 539-550.

Loetscher, T., Regard, M., \& Brugger, P. (2006). Misoplegia: a review of the literature and a case without hemiplegia. Journal of Neurology, Neurosurgery \& Psychiatry, 77(9), 1099-1100.

Mesulam, M. M. (1998). From sensation to cognition. Brain, 121(Pt 6), 1013-1052.

Marmor, G. S. (1977). Mental rotation and number conservation: are they related? Developmental Psychology, 13, 320-325.

Mewasingh, L. D., Sékhara, T., Pelc, K., Missa, A. M., Cheron, G., \& Dan, B. (2004). Motor strategies in standing-up in children with hemiplegia. Pediatric Neurology, 30(4), 257-261.

Morris, C. (2007). Definition and classification of cerebral palsy: a historical perspective. Developmental Medicine and Child Neurology Supplement, 109, 3-7.

Morris, J.P., Pelphrey, K.A., \& McCarthy, G. (2006). Occipitotemporal activation evoked by the perception of human bodies is modulated by the presence or absence of the face. Neuropsychologia, 44, 1919-1927.
Murata, A., \& Ishida, H. (2007). Representation of bodily self in the multimodal parieto-premotor network. In: S. Funahashi (Ed.), Representation and brain (pp. 151-176). Tokyo: Springer.

Parsons, L.M. (1987). Imagined spatial transformation of one's body. Journal of Experimental Psychology: General, 116, 172-191.

Parsons, L. M., Fox, P. T., Downs, J. H., Glass, T., Hirsch, T. B., Martin, C. C., ... \& Lancaster, J. L. (1995). Use of implicit motor imagery for visual shape discrimination as revealed by PET. Nature, 375(6526), 54-58.

Peelen, M.V., Atkinson, A.P., Andersson, F., \& Vuilleumier, P. (2007). Emotional modulation of body-selective visual areas. Social Cognitive \& Affective Neuroscience, 2, 274-283.

Peelen, M.V., \& Downing, P.E. (2005). Is the extrastriate body area involved in motor actions? Nature Neuroscience, 8(2), 125-126.

Peelen, M.V., \& Downing, P.E. (2007). The neural basis of visual body perception. Nature Reviews Neuroscience, 8, 636-648.

Peelen, M.V., Wiggett, A.J., \& Downing, P.E. (2006). Patterns of fMRI activity dissociate overlapping functional brain areas that respond to biological motion. Neuron, 49(6), 815-822.

Punt, T.D., \& Riddoch, M.J. (2006). Motor neglect: implications for movement and rehabilitation following stroke. Disability and Rehabilitation, 28(13-14), 857-864.

Rethlefsen, S.A., Ryan, D.D., \& Kay, R.M (2010). Classification systems in cerebral palsy. Orthopedic Clinics of North America, 41(4), 457-467.

Schwarzlose, R.F., Baker, C.I., \& Kanwisher, N. (2005). Separate face and body selectivity on the fusiform gyrus. Journal of Neuroscience, 25, 11055-11059.

Schwoebel, J., Buxbaum, L.J., \& Coslett, H.B. (2004). Representations of the human body in the production and imitation of complex movements. Cognitive Neuropsychology, 21, 285-298.

Schwoebel, J., \& Coslett, H.B. (2005). Evidence for multiple, distinct representations of the human body. Journal of Cognitive Neuroscience, 17(4), 543-553.

Sirigu, A., Duhamel, J.R., Cohen, L., Pillon, B., Dubois, B, \& Agid, Y. (1996). The mental representation of hand movements after parietal cortex damage. Science, 273(5281), 1564-1568.

Sirigu, A., Grafman, J., Bressler, K., \& Sunderland, T. (1991). Multiple representations contribute to body knowledge processing: evidence from a case of autotopagnosia. Brain, 114, 629-642.

Taylor, J.C., Wiggett, A.J., \& Downing, P.E. (2007). Functional MRI analysis of body and body part representations in the extrastriate and fusiform body areas. Journal of Neurophysiology, 98, 1626-1633.

Watkins, S., \& Rosenberg, A. (2002). Cerebral palsy. In: V.S. Ramachandran (Ed.), Encyclopedia of the human brain (vol. 1, pp. 703-714). San Diego: Academic Press. 